


\section{MASSACHUSETTS INSTITUTE OF TECHNOLOGY $P$ L A S M A F U S I O N C E N T E R}
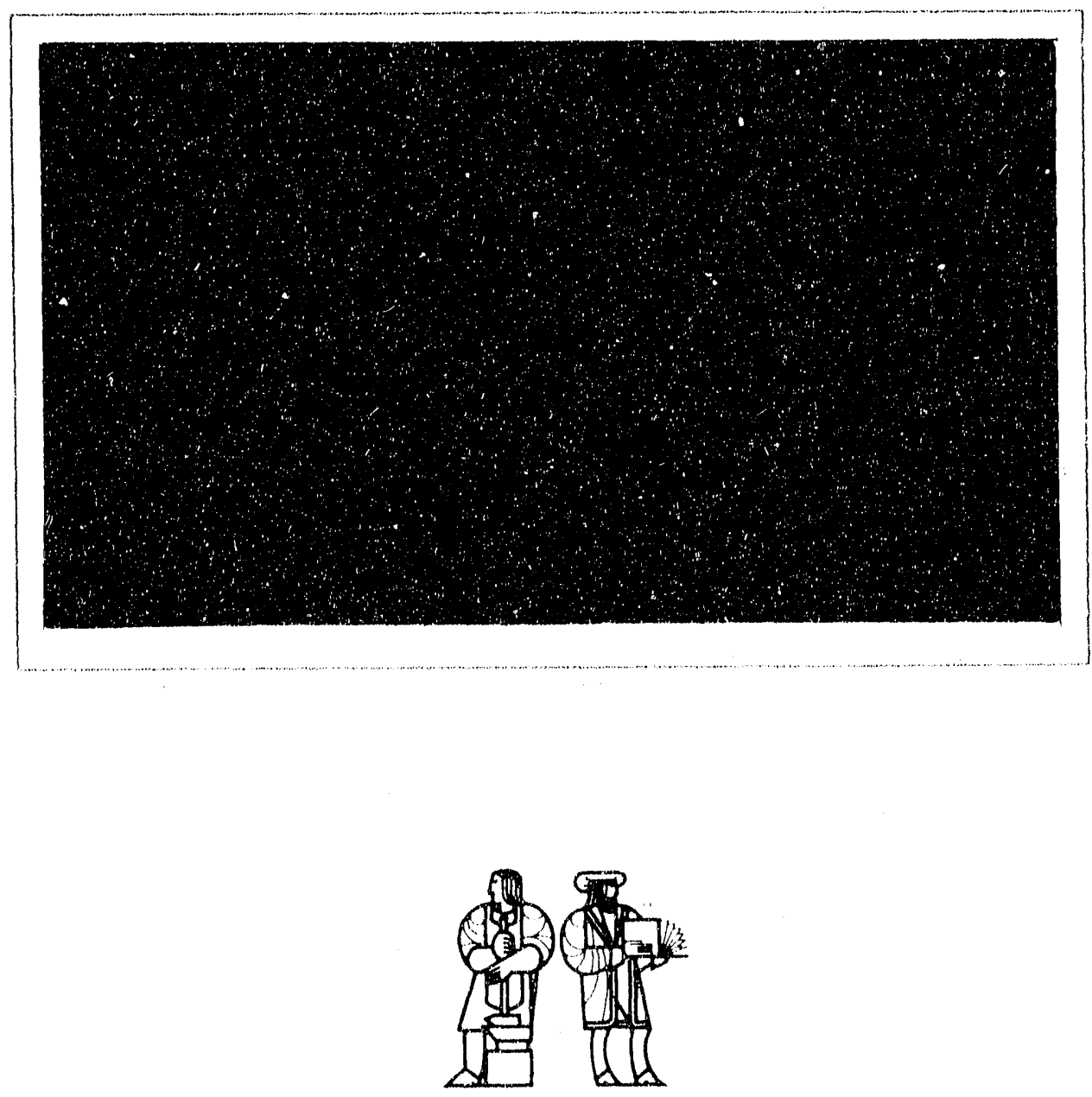

CAMBRIDGE, MASSACHUSETTS 02139

ASSOCIATED WITH

DEPARTMENT OF ELECTRICAL, ENGINEERINC; ANI) COMPUTER SLIENCE

DEPARTMENT OF MATERIALS SCIENCE

AND ENGINEERINO

DEPARTMENT OF MEL HANICAL ENGINEFRING;

DEPARTMENT OF NUII:AR ENGINEERINC;

DEPARTMENT OF PHYSICS

FRANCIS BITTER NATIUNAL MA(INET LABCIRATC)RY'

RESEARCH LABORATORY (IF ELEOTRONICS 
PFC/RR-92-2

\title{
DC CICC Retrofit Magnet Preliminary Design, Software Development and Analysis Report
}

\author{
Quarterly Progress Report \\ Contract No. DE-FG22-90PC90350 \\ January 1992 \\ R. Leonard Myatt and P.G. Marston
}

Submitted February 10, 1992

\begin{abstract}
DISCLAIMER
This report was prepared as an account of work sponsored by an agency of the United States Government. Neither the United States Government nor any agency thereof, nor any of their employees, makes any warranty, express or implied, or assumes any legal liability or responsibility for the accuracy, completeness, or usefulness of any information, apparatus, product, or process disclosed, or represents that its use would not infringe privately owned rights. Reference herein to any specific commercial product, pr eess, or service by trade name, trademark, manufacturer, or otherwise does not necessarily constitute or imply its endorsement, recommendat $\backsim$, or favorinn by the Unied Staies Government or any agency thereof. The views and opiniont of authors expressed herein du not necessarily state or reflect those of the United States Government or any agency thereol.
\end{abstract}

\author{
Massachusetts Institute of Technology \\ Plasma Fusion Center \\ 175 Albany Street \\ Cambridge, MA 02159
}




\subsection{Introduction}

The proposed retrofit coil is made of superconducting Cable-in-Conduit Conductcr (CICC). The coils are designed to produce a nominal vertical field of 4.5 tesla within the MHD channel based on a nominal current density of $13.05 \mathrm{MA} / \mathrm{m}^{2}$. The coils are supported within a case, or so-called constant tension strap. When the magnet is energized, the electromagnetic $J \times$ B body forces push the winding pack laterally outward and vertically towards the machine's midplane, thus putting the strap in tension. The end turns add axial tension to the conductor (a condition which is not simulated by this 2-D model of the midlength cross section). A sketch of the magnet system and structure is shown in Fig. 1.0-1.

The purpose of this report is to describe the progress made in the design and analysis of the DC CICC retrofit magnet, and to outline the proposed next step. The previous progress report' discusses a preliminary coil support concept and a 2-D finite element (FE) ANSYS ${ }^{2}$ model of the dipole cross section. As a result of this analysis, adjustments to the design and improvements to the model have been made to reduce the stresses and increase the reliability of the design. These changes have included adding a smooth elliptical shape to the coil cross section and tension strap, simplifications in the strap support concept, and the addition of a low friction slip plane between the strap and the conductor. The finite element model is used as a design tool to perform preliminary scoping studies such as exploring the effects of variations in the coil cross section, support strap thickness, and slip plane friction coefficient. The results presented here indicate that the 2-D model provides many insights into the fundamental characteristics of the machine.

The most recent work and the proposed next step in the design and analysis process focus on a 3-D model of the magnet system and structure. The complex field and forces which occur in the end turn regions of the magnet are highly three dimensional, and are best captured by a 3-D model with comparable complexity. An element plot of the 3-D model is presented and the proposed analysis is discussed. Results of the 3-D analysis will be presented in the next progress report.

'"DC CICC Retrofit Magnet Preliminary Design, Protection Analysis and Software Development," PFC/RR-91-10, J. Chen, P.G. Marston, J.R. Hale, and A.M. Dawson, Issued May, 1991, Plasma Fusion Center, MIT.

${ }^{2}$ ANSYS Engineering Analysis System, Rev. 4.4A, Swanson Analysis Systems, Inc., Houston, PA 


\subsection{Summary and Conclusions}

The 2-D finite element analysis indicates that the stresses in the coil and the $5 \mathrm{~cm}$ thick support strap are within reasonable design limits. The concept of a constant tension strap, which wraps like a wide belt around the straight section of the magnet system, works well in conjunction with a low friction slip plane. Results show a $\pm 13 \%$ variation in the stress across the thickness of the strap with an average stress of $157 \mathrm{MPa}$. By design, the stresses in the coil remain compressive in the vertical and lateral directions. In addition, the analysis indicates that turn-to-turn and pancake-to-pancake interfaces will remain motionless providing the coils are bonded with a minimum shear strength of about $3 \mathrm{MPa}$.

\subsection{Analysis Description}

The analysis described herein is designed to evaluate the global structural behavior of the semi-elliptical coil cross section, support strap, low friction interface, and field homogeneity. The electromagnetic and structural evaluation is based on a 2-D nonlinear finite element analysis of the coil and support strap. The modeling process takes advantage of two symmetry planes to minimize the model size and computation time. Figure 3.0-1 shows the finite element model.

\subsection{Modeling Details}

The model is generated within the ANSYS PREP7 preprocessor. The geometry is defined by parameters which greatly simplify the inevitable changes to the model which occur during the analysis process. Changes such as mesh density, coil build and construction radii can be accommodated by simply redefining numbers in the parameter list. For example, the conductor element density is easily varied by changing the parameter $\mathrm{NEC}=5$, which is a user-defined abbreviation for the Number of Elements in the Coil.

The nature of the analysis and its objectives establish the level of detail that must be included in the model. On this basis, the actual winding pack (i.e., insulation, conductor, conduit) is approximated by smeared orthotropic material properties (Young's Modulus: $E_{x}, E_{y}, E_{z}$; Poisson's Ratio: $v_{x y}, v_{y z}$ and $v_{x z}$ ). These properties are calculated such that the global structural characteristics of the saddle coil are represented. The material properties associated with the strap are simply isotropic constants.

The electromagnetic boundary conditions $(\mathrm{BC})$ of the problem are chosen by visualizing the flux path and identifying flux-normal and flux-parallel symmetry planes. The vertical field at the vertical symmetry plane indicates the need for a flux-parallel $\mathrm{BC}$. For the vector potential formulation, this is achieved by setting the potential $A_{2}$ (or MAG in ANSYS language) to zero for all nodes along this boundary. The vertical field at the horizontal symmetry plane indicates a flux-normal condition, which is the "natural" $\mathrm{BC}$ for the vector potential solution. No condition on $A_{z}$ is required.

The vector potential solution also requires modeling the air out to an "infinite boundary," often results in air elements which exceed the number of structural elements. This is simplified greatly by the use of so-called 2-D boundary elements. Placed at a conveniently located far field 
boundary, these boundary elements capture the effect of semi-infinite space without requiring the discrete definition of air elements out to infinity. These magnetic field $\mathrm{BCs}$ are depicted in Fig. $3.1-1$.

The displacement boundary conditions for the structural analysis are almost trivial. Full machine behavior is achieved by specifying zero vertical displacements for all nodes which lie on the horizontal symmetry plane, and zero lateral displacements for all nodes which lie on the vertical symmetry plane. These BCs are shown for structural elements in Fig. 3.1-2.

The model is loaded electromagnetically by a uniform current density of $13.05 \mathrm{MAT} / \mathrm{m}^{2}$, which produces a nominal 4.5 tesla at the machine axis. In the first "iteration" the program solves the magnetics problem. $J \times B$ body forces are also calculated and saved automatically as input to the next "iteration" which is the structural solution. The analysis is only complete when the nonlinear gap elements with friction have converged as the coil strains and slips within the confines of the strap.

\subsection{Variables in the Analysis}

A series of computer runs is made to characterize the behavior of the coil, strap and the effects of their interaction. The series includes variations in coil profile (achieved by varying the lateral build of the coil cross section while maintaining the baseline vertical half build of 0.88 meters), variations in the strap thickness, and variations in the slip surface friction coefficient (ranging from frictionless to stuck). The most illustrative and conclusive results are presented below in section 4.0 .

\subsection{Results}

Although a yariety of builds is analyzed, the cross section with a nominal build of 0.72 meters wide and a half height of 0.88 meters represents a coil which operates right at the design current density of about $13 \mathrm{MAT} / \mathrm{m}^{2}$. As the lateral build of the coil is increased from 0.72 meters to 1.08 meters, its cross-sectional area increases by $50 \%$ and the location of the current center move's away from the channel. The effect is an increase in the current required to produce the 4.5 tes $1 / \mathrm{L}$ field, and a $27 \%$ drop in the current density to $9.6 \mathrm{MAT} / \mathrm{m}^{2}$, well below the design value. The wider build coil operates at lower Von Mises and shear stress levels (by about a factor of 2). However, at this level of analysis, the stresses in the baseline coil cross sertion are not a limiting factor, and the narrower $0.72 \mathrm{~m}$ build offers a more optimum design.

The coefficient of friction between the coil and strap determines, to a great extent, the level of shear and tensile stresses in the coil. While a fully stuck strap produces turn-to-turn and pancake-to-pancake tensile stresses of $16 \mathrm{MPa}$ and $11 \mathrm{MPa}$, respectively, a free sliding interface does not produce any tensile stresses. The analysis shows that compression throughout the coil is maintained even with a friction coefficient of 0.1 .

Variations in the strap thickness have little effect on the results other than to change the stress level of the strap itself. A nominal strap thickness of $5 \mathrm{~cm}$ appears to be sufficient at this level of analysis. 


\subsection{Graphical Output}

The series of plots which follow summarize the results of the new baseline design, which is a $0.72 \mathrm{~m}$ by $1.76 \mathrm{~m}$ coil build, a $5 \mathrm{~cm}$ thick strap, and a friction coefficient of 0.1 .

Figure 4.1-1 shows a flux plot of the entire model, including the air elements out to the $3 \mathrm{~m}$ boundary. The results seem to make sense, and the boundary conditions and boundary elements appear to be working. The flux is parallel at the vertical symmetry plane, normal at the horizontal symmetry plane and neither parallel nor normal at the $3 \mathrm{~m}$ radius, a condition one would expect at a boundary so close to the magnet. Incidently, analyses indicate that variations in the position of this radial boundary have almost no effect on the field results.

Figure $4.1-2$ is a plot of the field homogeneity within a $0.27 \mathrm{~m}$ wide by $0.34 \mathrm{~m}$ tall quarter window. The figure indicates a variation about $4.5 \mathrm{~T}$ of $+2.6 \%$ to $-1.1 \%$, well within the $\pm 5 \%$ design criteria.

Figure 4.1-3 shows the displaced shape of the coil and strap cross section superimposed on an undisplaced element plot. As a matter of interest, $\mathrm{J} \times \mathrm{B}$ force vectors are shown in Fig. 4.1-3a to demonstrate the complicated force field which so often is reduced to net lateral and vertical scalars at the hand-calculation level of analysis.

Figure 4.1-4 shows the SX stress in a coordinate system which is parallel to the strap (the equivalent of hoop stress in a thin wall vessel). The most significant result is the very small amount of bending in the strap. The variation from the average stress is less than $20 \%$. In addition the peak stress is only about $180 \mathrm{MPa}$.

Figures 4.1-5, 6, 7 and 8, respectively, show plots of the lateral (SX), vertical (SY), shear (SXY), and Von Mises equivalent (SIGE) stresses in the coil cross section. These plots represent the stress levels in the smeared conductor material. To convert SX and SY from smeared values to say conduit stresses, the results must be scaled by the ratio of the moduli. Here, the scale factor is 5.7 , which makes the largest compressive stress (42.4 MPa smeared value) about 240 $\mathrm{MPa}$. Although the SX stress is small where the vertical stress is large, this analysis does not include the axial stress term ${ }_{\star}$ which will add directly to the stress intensity at the $240 \mathrm{MPa}$ midplane location. This stress component will be determined by the proposed 3-D analysis.

The final two stress plots, Figs. 4.1-9 and 10, show a derived quantity called "Shear Margin." The value represents the amount of shear stress the coil can sustain without experiencing relative motion. The spatial dependent quantity is determined by multiplying the local compressive stress (SX or SY) by an estimated friction coefficient (say 0.3 ), and subtracting the magnitude of the local shear stress. MRGX represents the turn-to-turn shear margin, and MRGY represents the pancake-to-pancake shear margin. For regions of positive shear margin, the friction capacity produced by the local compression is sufficient to sustain a no-slip interface. For regions of negative shear margin, the friction capacity must be supplemented by bonding the surfaces with an adhesive which will add at least the indicated shear strength. These figures indicate that a relatively small fraction of the coil must be bonded with a nominal shear capacity of $1 \mathrm{MPa}$ between pancakes and $3 \mathrm{MPa}$ between turns.

Two series of stress results are summarized in Table 4.1-1 below. In the baseline case, the slip plane between the coil and the strap is modeled with a friction coefficient of 0.1 . A preliminary review of these results indicates an acceptable stress condition for the conductor and insulation. In the contrasting extreme case, the interface between the coil and the strap is modeled 
as a no-slip condition, and the results indicate an unacceptable state of stress. There are increases in the vertical, Von Mises equivalent, and shear stresses. In addition, the bonding requirements of the coil increase by a factor of 5, while large regions of the coil experience turn-to-turn and pancake-to-pancake tension. This indicates that the design must incorporate some form of slip surface between the coil and the structure.

Table 4.1-1: Summary of Significant Stress Results

\begin{tabular}{|c|c|c|c|c|c|c|c|}
\hline \multirow{2}{*}{$\begin{array}{c}\text { Case } \\
\text { Description }\end{array}$} & \multicolumn{6}{|c|}{ Coil Stress (MPa) } & \multirow{2}{*}{$\begin{array}{c}\text { Strap } \\
\text { Stress } \\
\text { (MPa) }\end{array}$} \\
\hline & $\begin{array}{l}\text { Lateral } \\
\quad \text { SX. }\end{array}$ & $\begin{array}{c}\text { Vertical } \\
\text { SY }\end{array}$ & $\begin{array}{l}\text { Smeared } \\
\text { Equival't } \\
\text { SIGE }\end{array}$ & $\begin{array}{l}\text { Shear } \\
\text { SXY }\end{array}$ & $\begin{array}{l}\text { Tum-to- } \\
\text { Turn } \\
\text { Shear } \\
\text { Margin }\end{array}$ & $\begin{array}{l}\text { Pan-to- } \\
\text { Pan } \\
\text { Shear } \\
\text { Margin }\end{array}$ & \\
\hline $\begin{array}{c}\text { Baseline } \\
\text { Case } \\
\mathrm{FC}=0.1\end{array}$ & $\begin{array}{c}-13.3 \\
\text { to } \\
-0.1\end{array}$ & $\begin{array}{l}-42.4 \\
\text { to } \\
-2.5\end{array}$ & 38.4 & 4.7 & -2.9 & -0.9 & 179 \\
\hline $\begin{array}{c}\text { Extreme } \\
\text { Case } \\
\text { Fully Siuck }\end{array}$ & $\begin{array}{c}-13.1 \\
\text { to } \\
15.5\end{array}$ & $\begin{array}{c}-53.0 \\
\text { to } \\
11.1\end{array}$ & 48.0 & 13.2 & $-11.9^{7}$ & $-15.5^{7}$ & 190 \\
\hline
\end{tabular}

Notes:

1. Coil build: $0.72 \mathrm{~m}$ wide $\times 1.76 \mathrm{~m}$ tall

2. Strap thickness: $5 \mathrm{~cm}$

3. Field strength: $4.5 \mathrm{~T}$

4. Results from 2-D model of coil mid-length; end turn effects not included.

5. Conductor conduit stresses can be obtained by scaling SX and SY by the actual-to-smeared modulus ratio: 5.7 .

6. $\mathrm{FC}=$ Friction Coefficient

7. Shear Margin calculation inappropriate and unconservative where tensile stresses exist in coil. 


\subsection{Proposed Future Work}

The 2-D analysis presented here demonstrates the attractiveness of the constant-tension strap coil support concept. It also serves as an effective design optimization tool. However, the complexities associated with the magnet and support system demands a more detailed inspection of the magnetic fields and structure. In fact, the magnets most vulnerable region (the end turns) can only be captured by a full 3-D finite element model. To this end, work has begun on a detailed 3-D moriel.

Figure 5.0-1 shows an isometric view of a 3-D electromagnet structural model in its early stages of development. The analysis requires that all current carrying elements are present for the electromagnetic field analysis. However, the structural analysis phase of the solution can make use of symmetry plane boundary conditions. Neglecting the slight taper along the coil axis allows a $1 / 8$ th symmetry structural model as shown. The support structure is presently limited to the strap, which extends from the half-length of the magnet into the end turn region. The structure must also include material to support the end turns around the channel. This is work in progress, the goal of which is to produce an efficient and effective coil support structure for the CICC retrofit magnet system. 


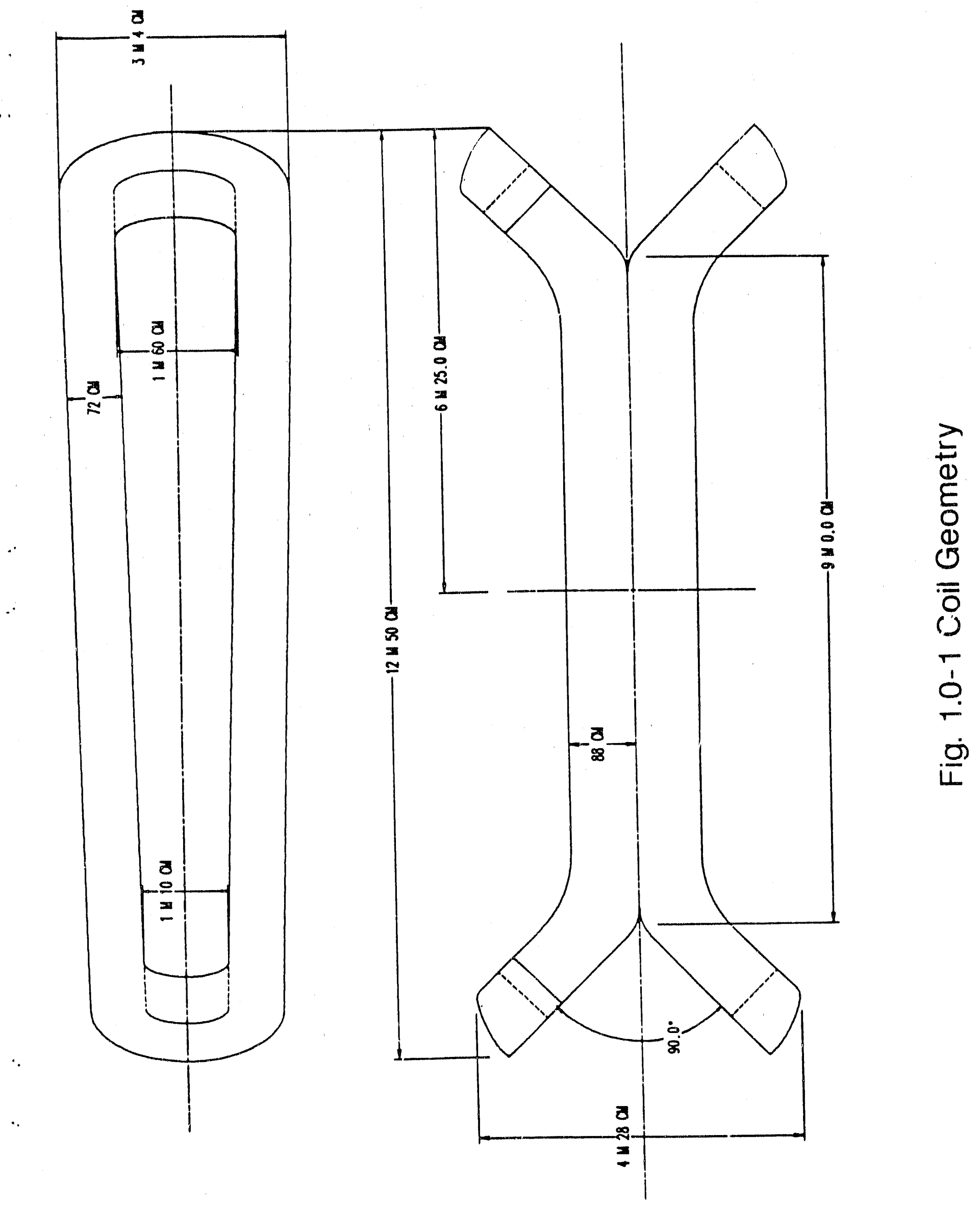




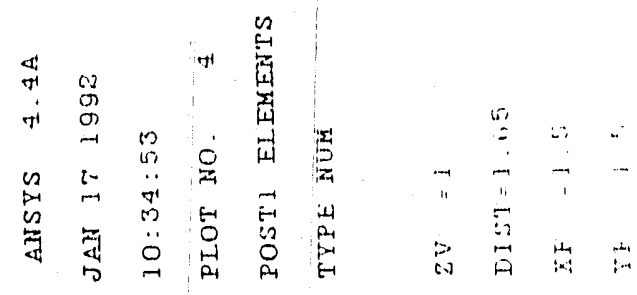

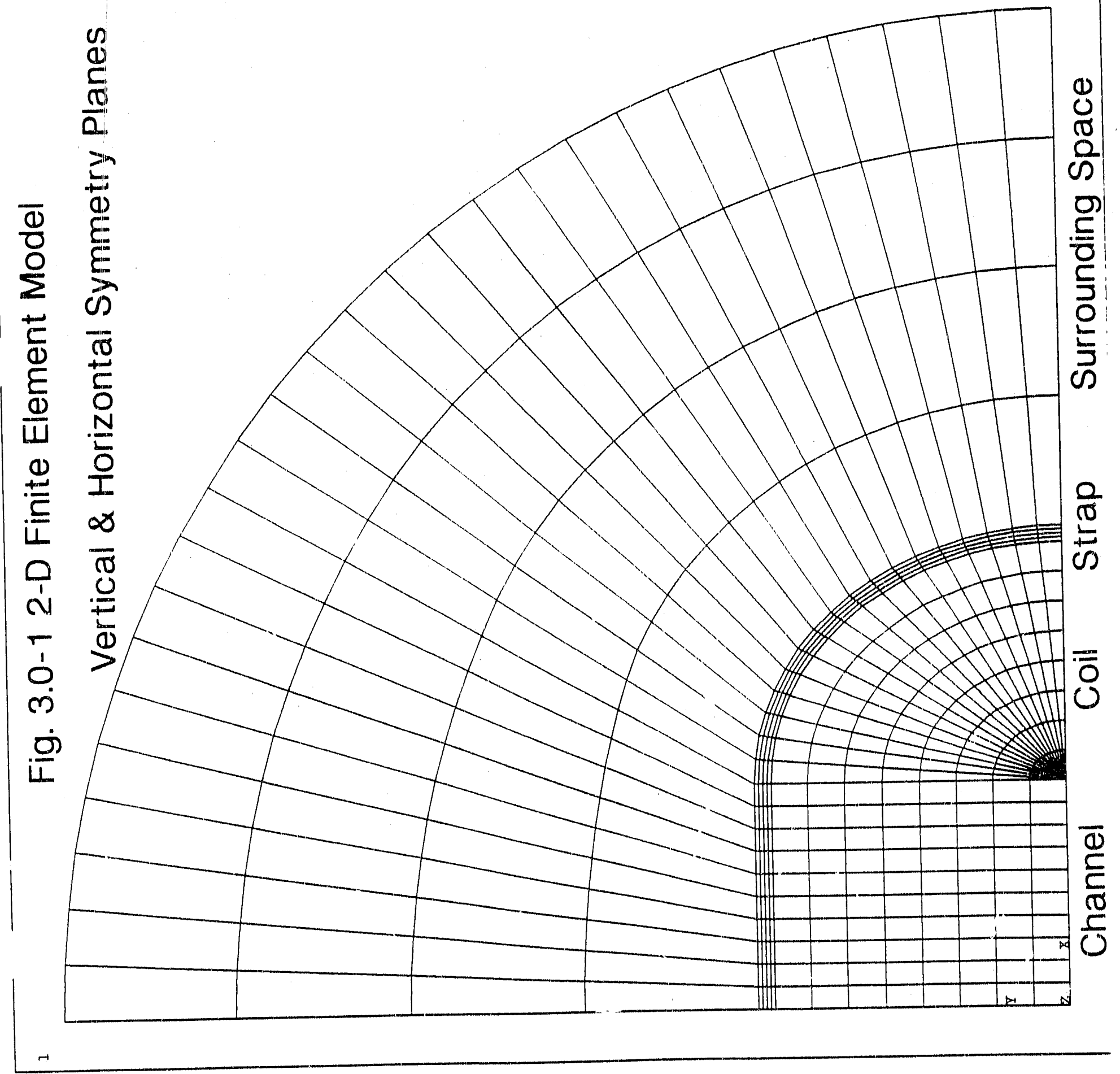



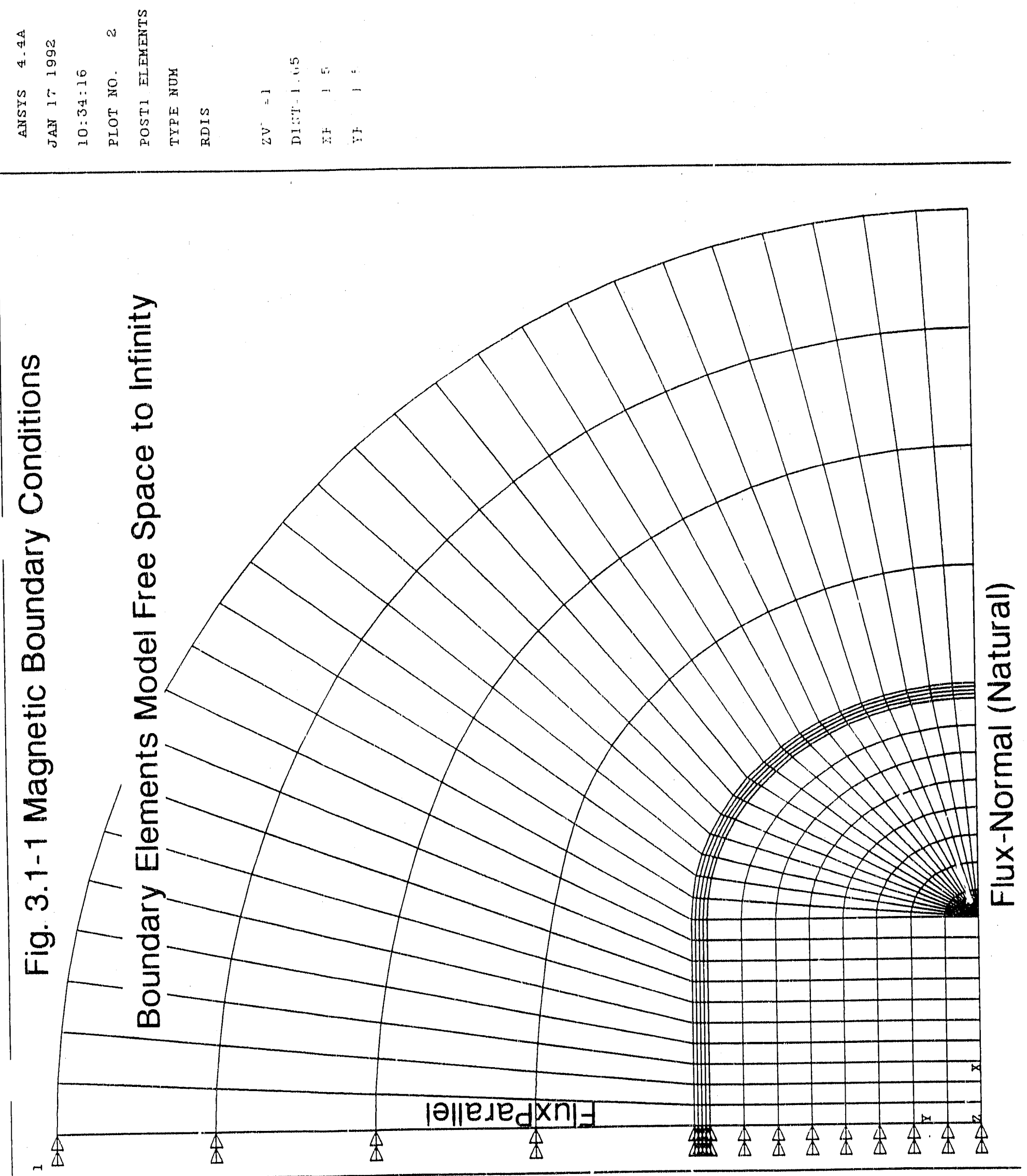


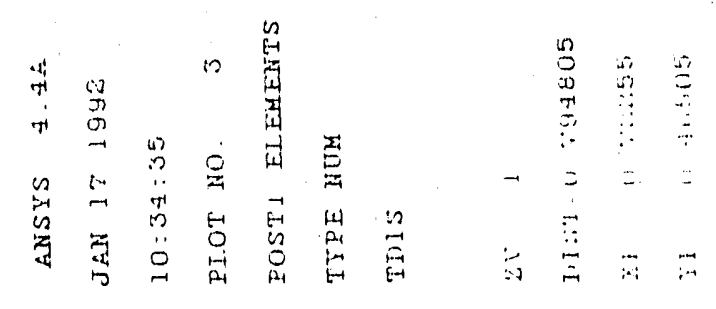

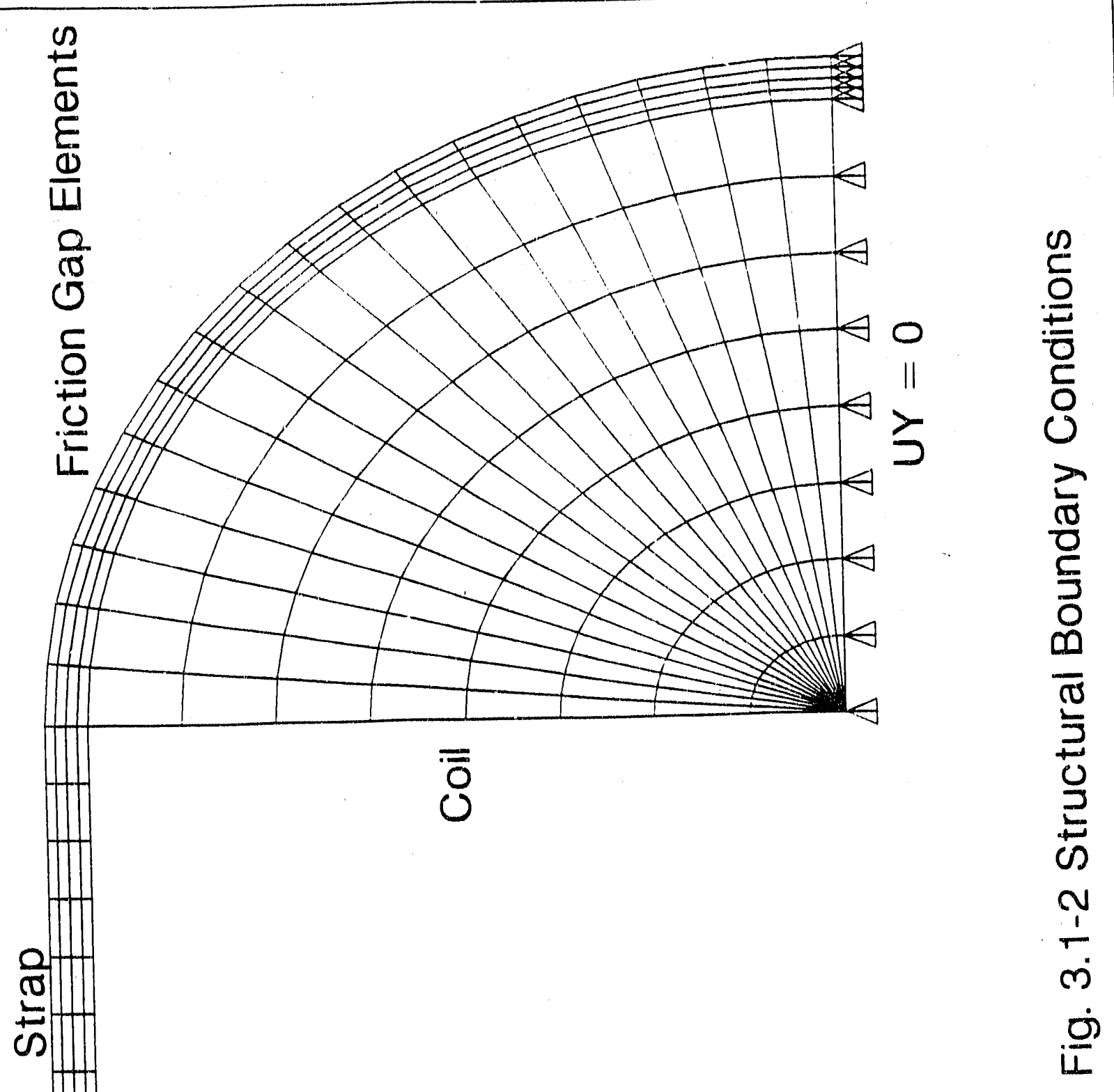




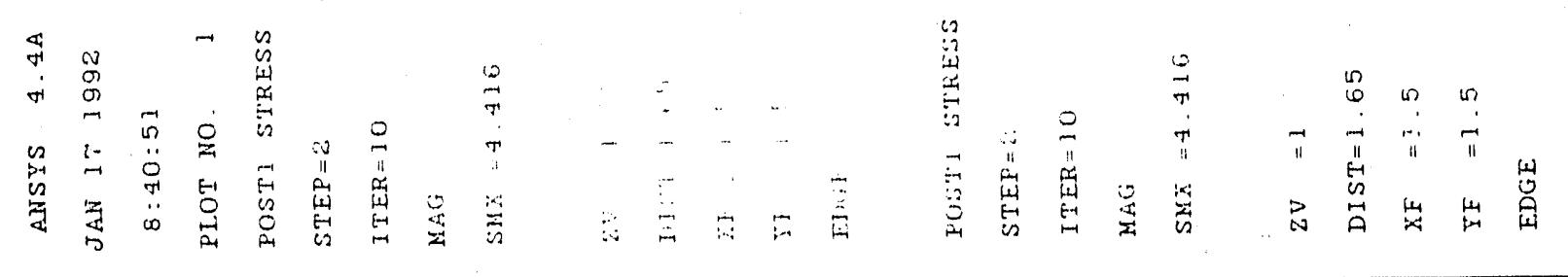

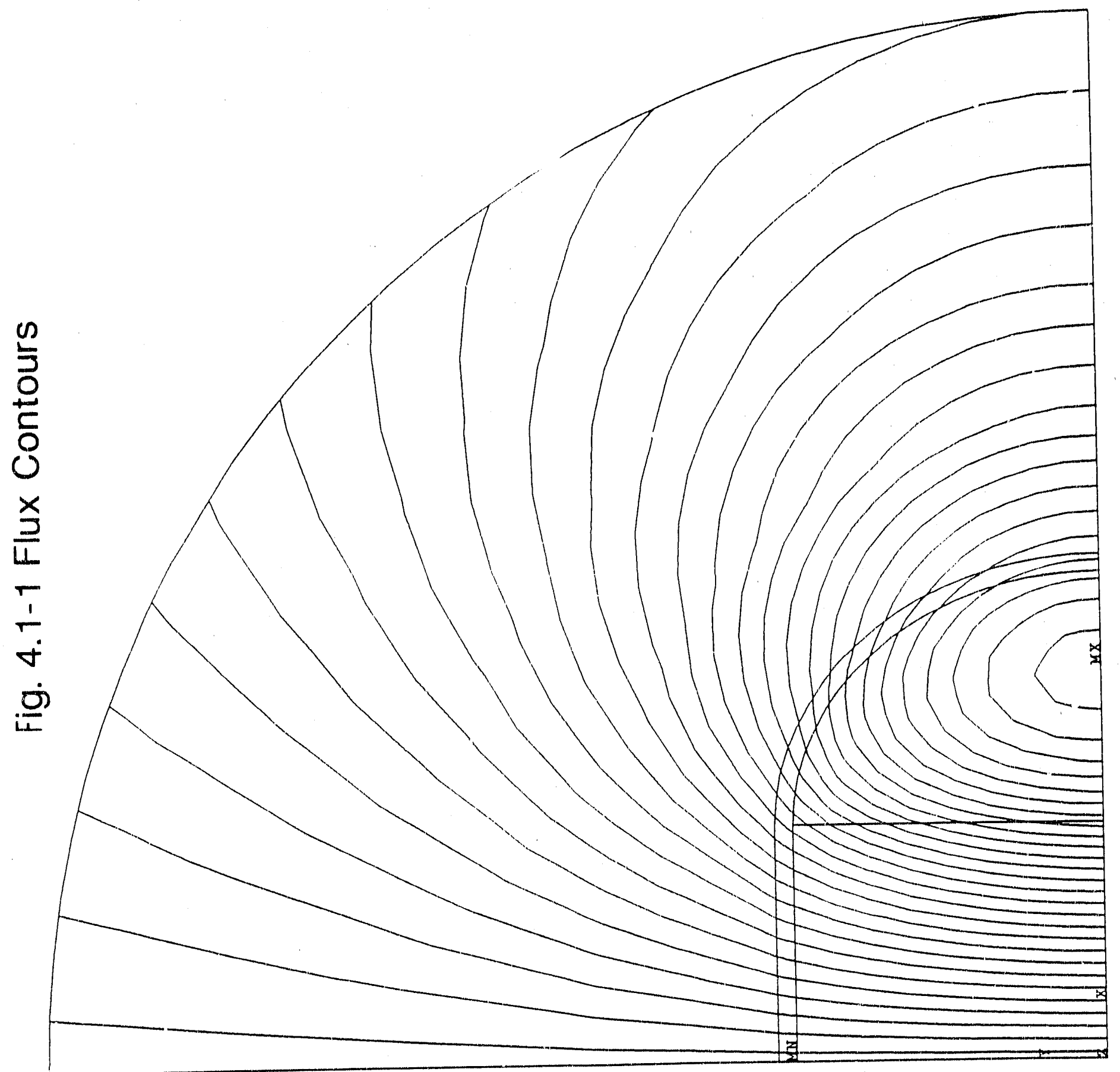

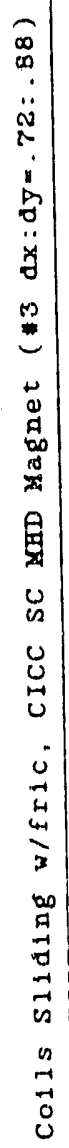




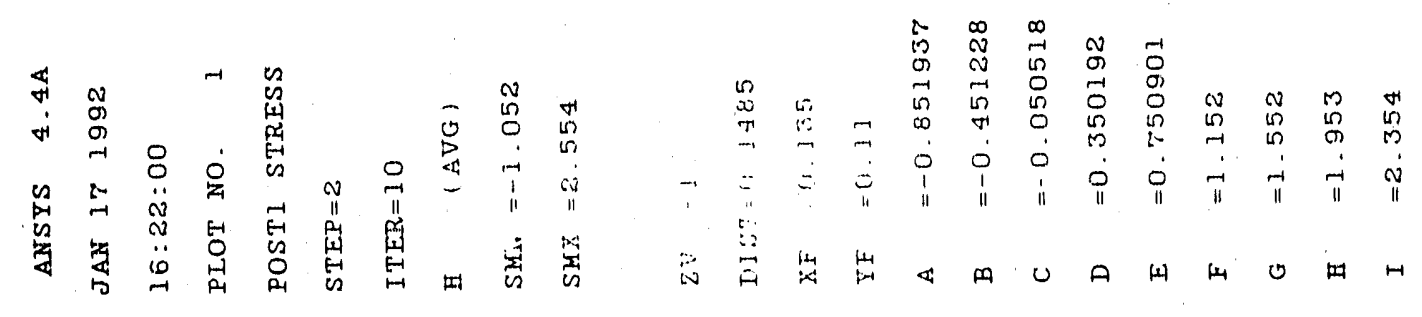

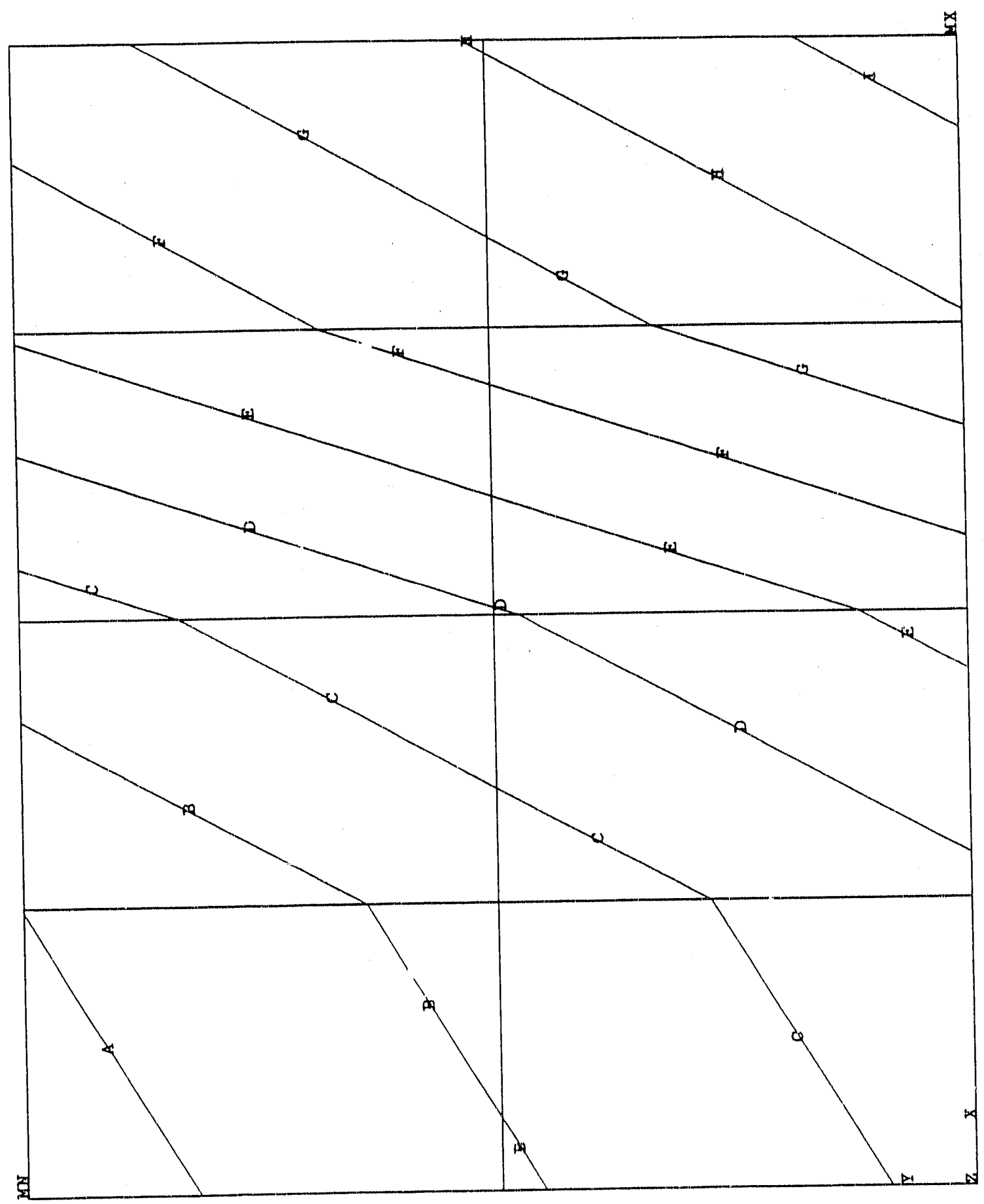

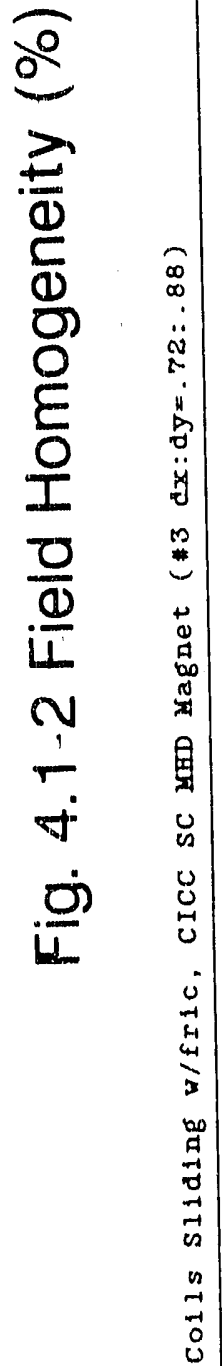




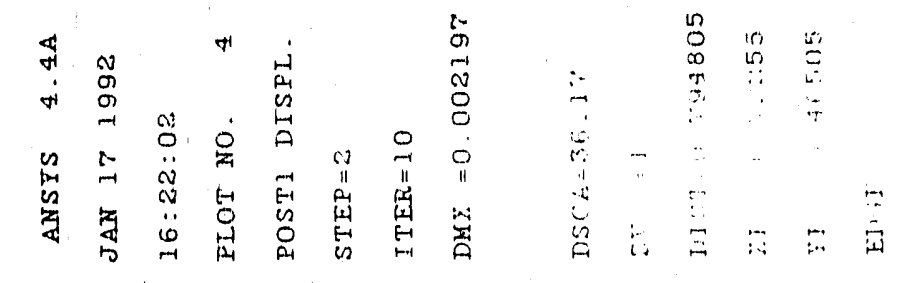

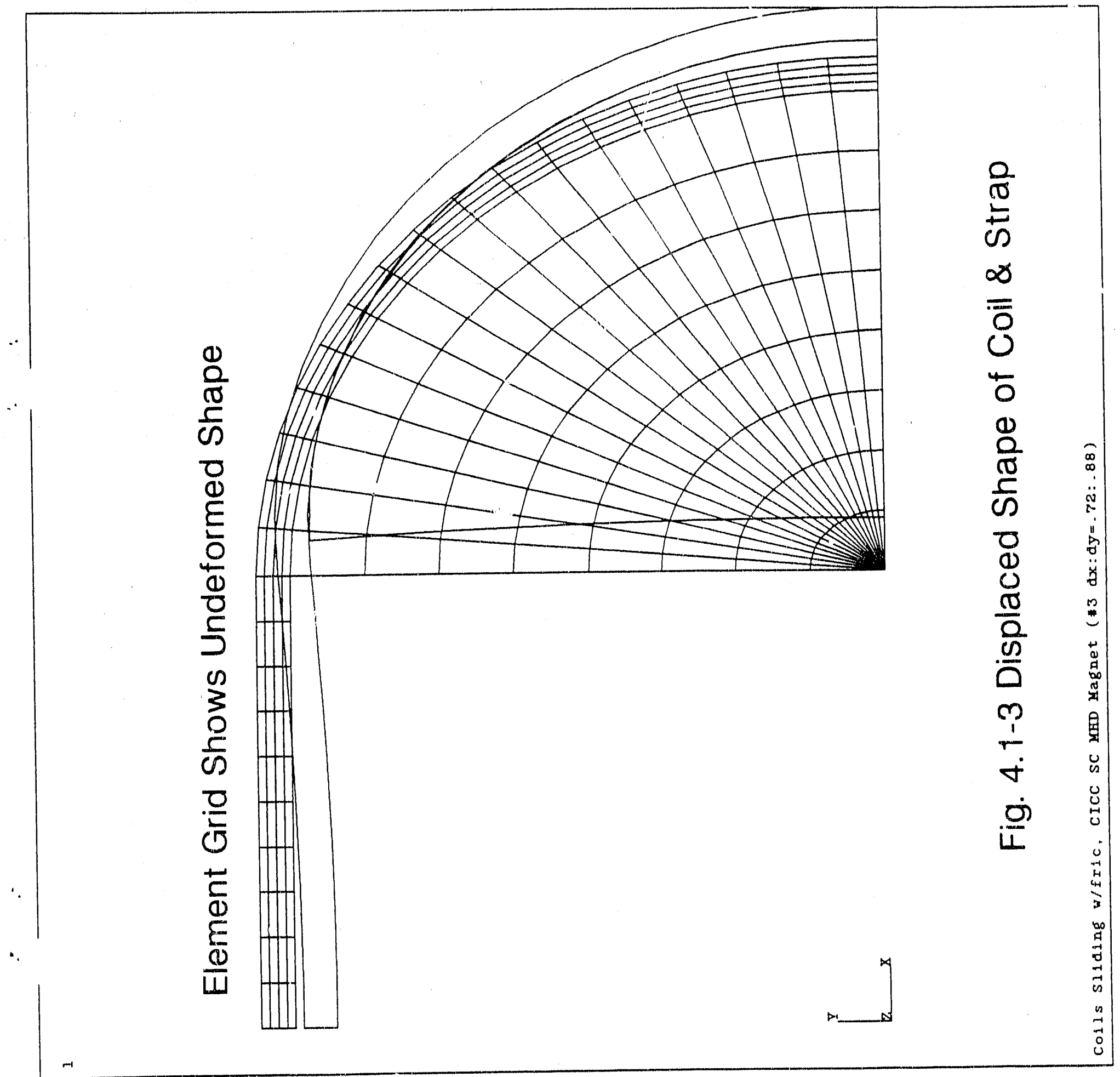




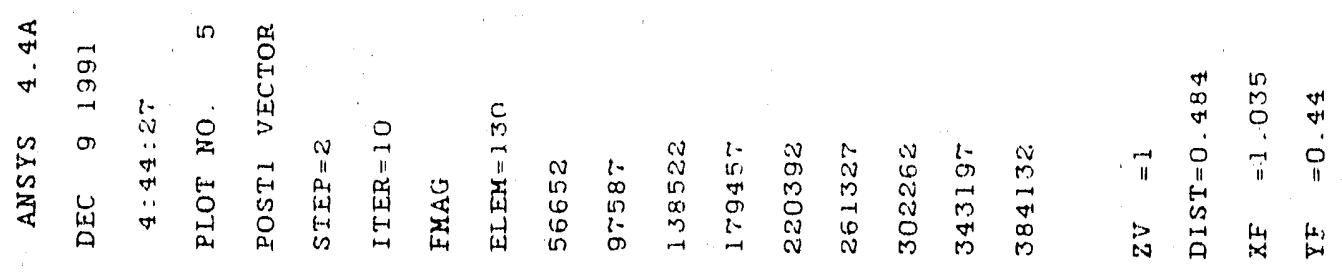

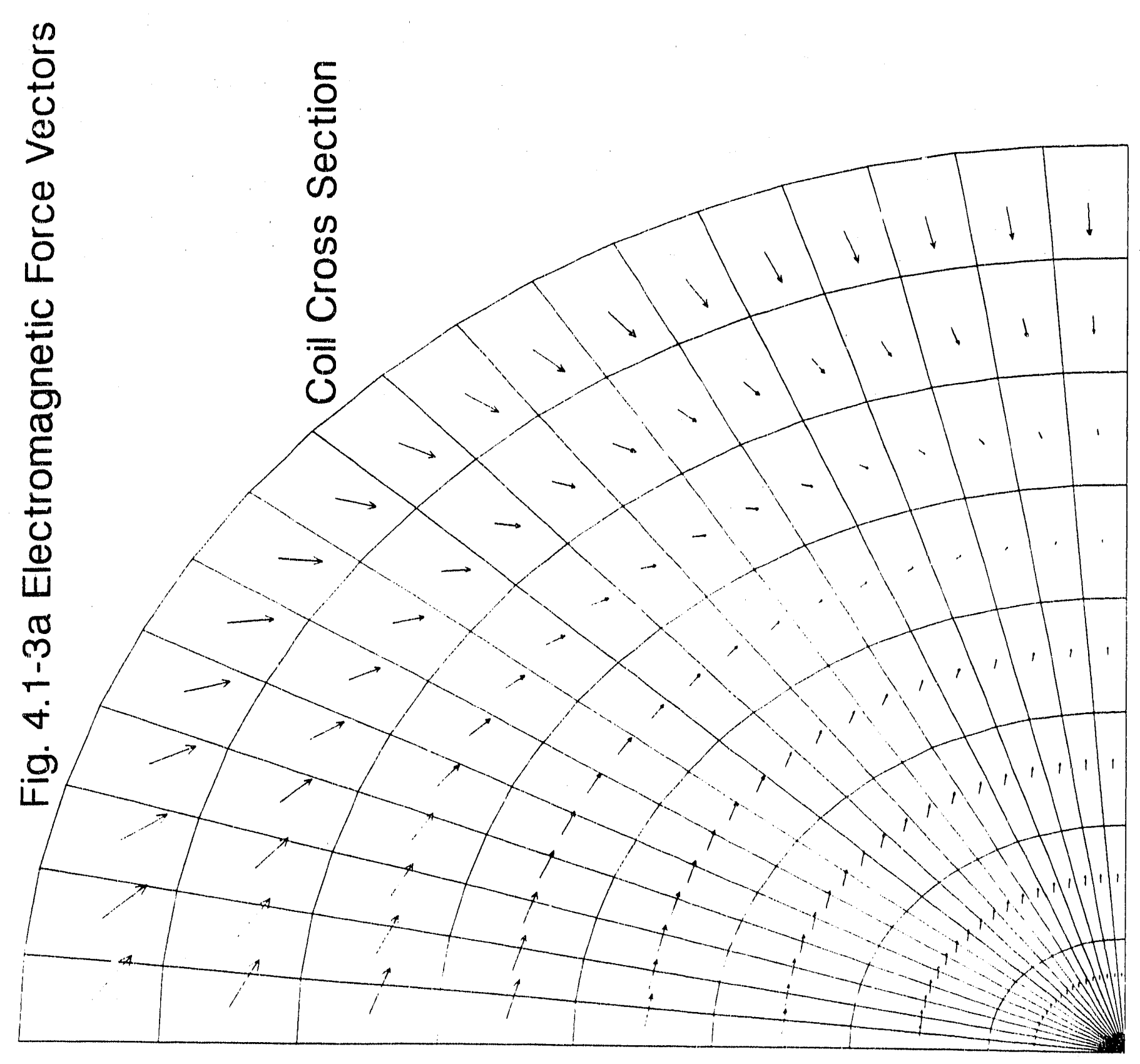

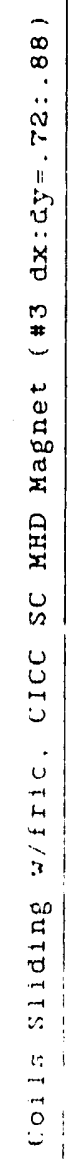




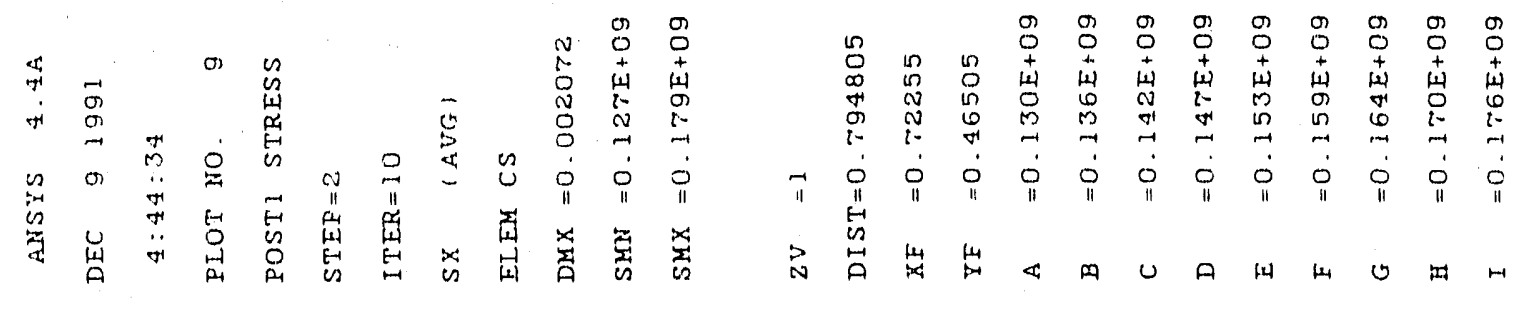

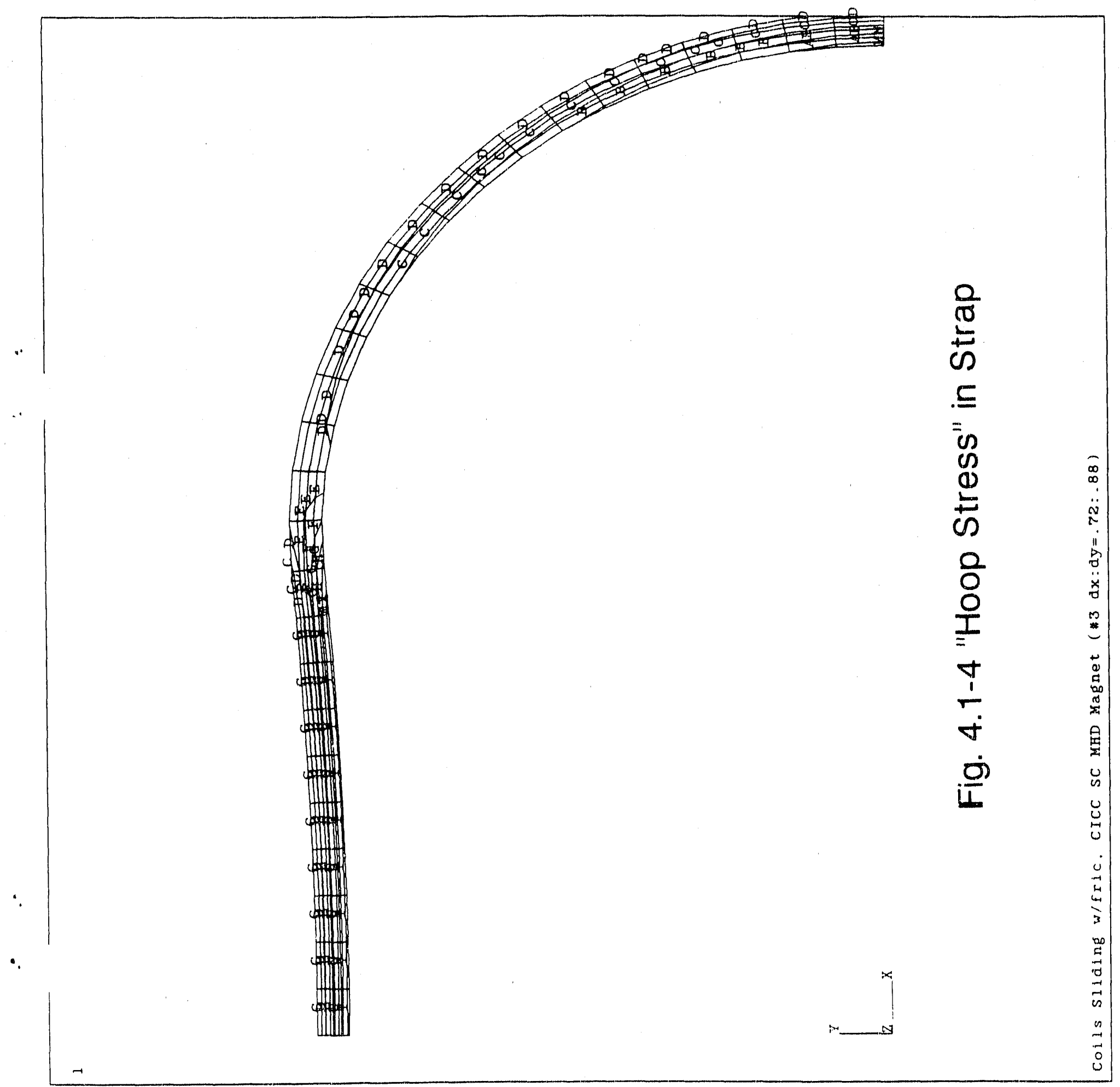




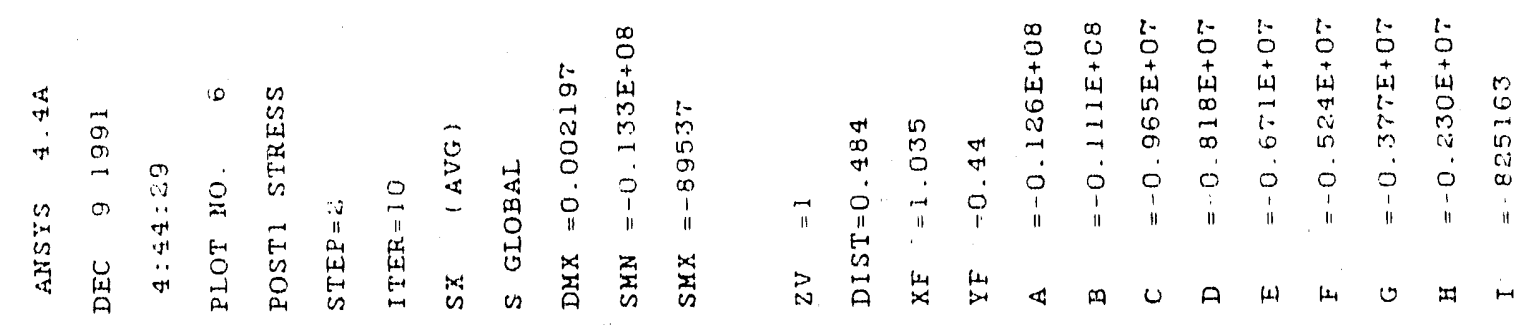

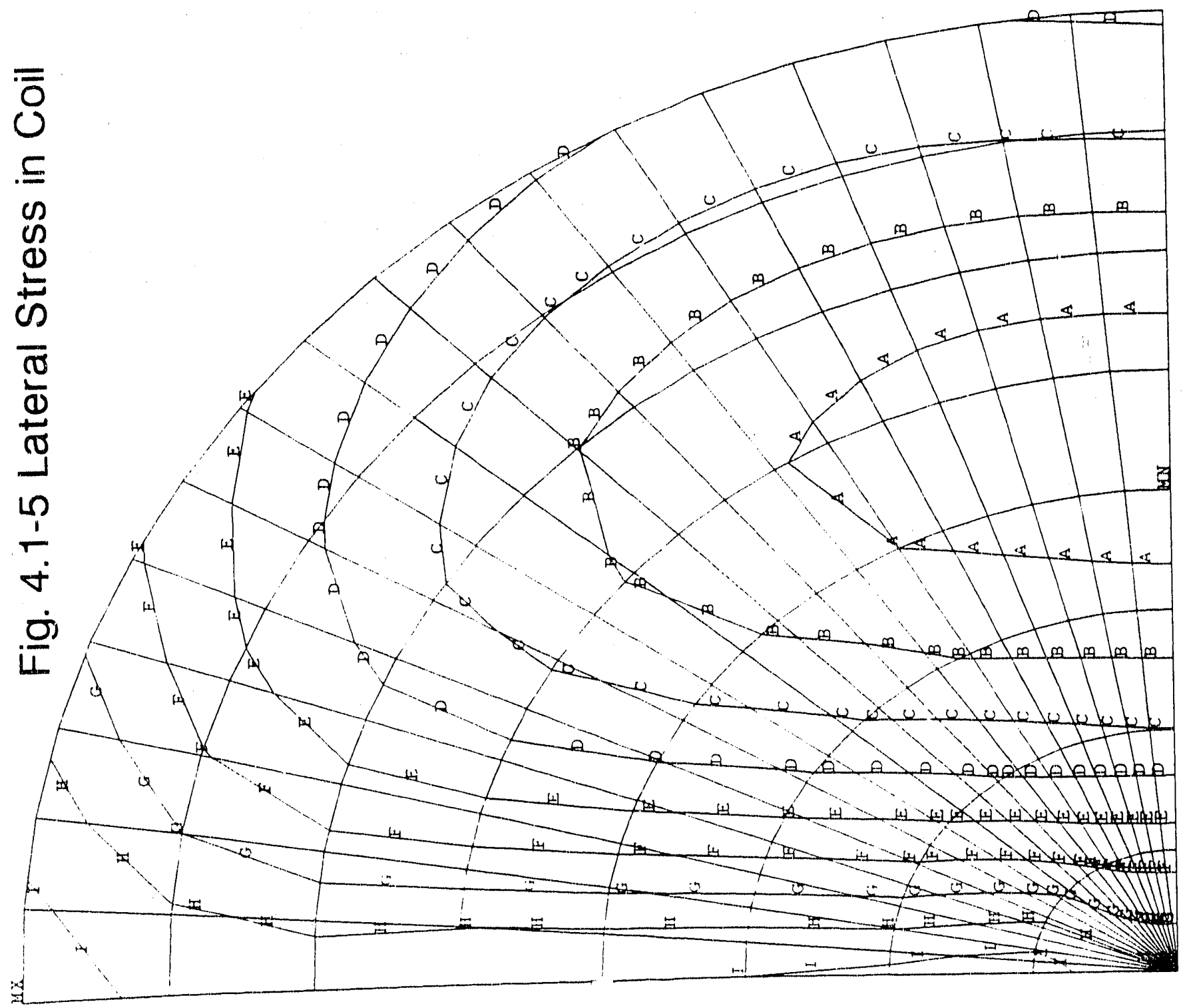




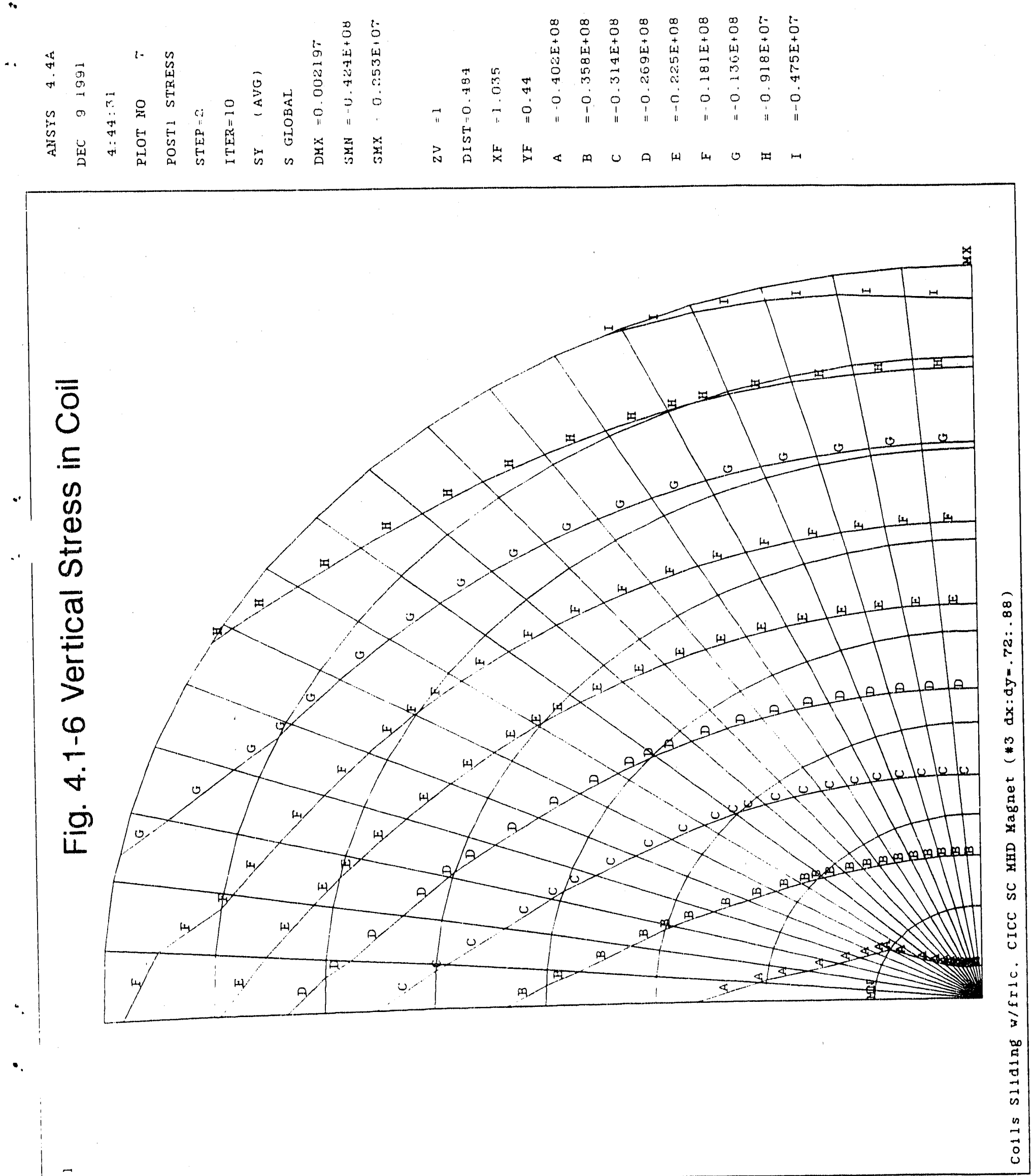




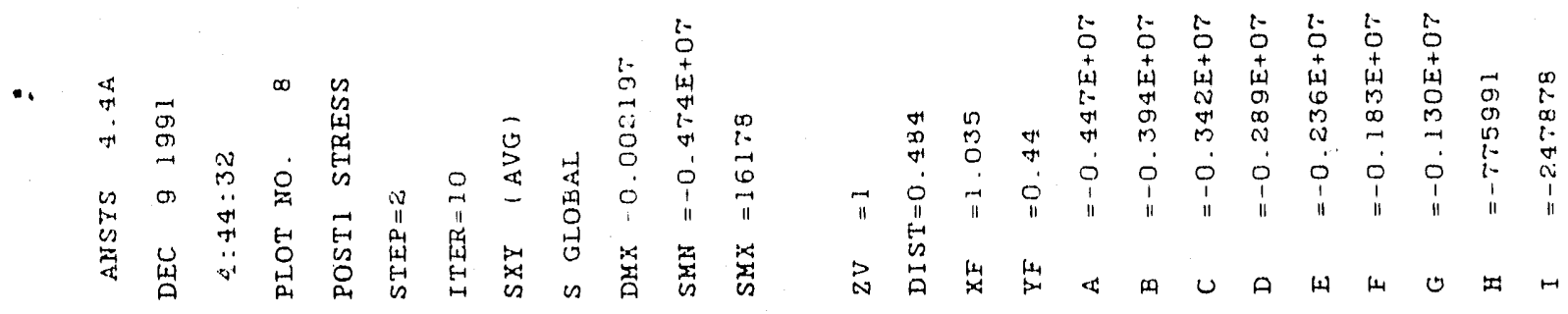

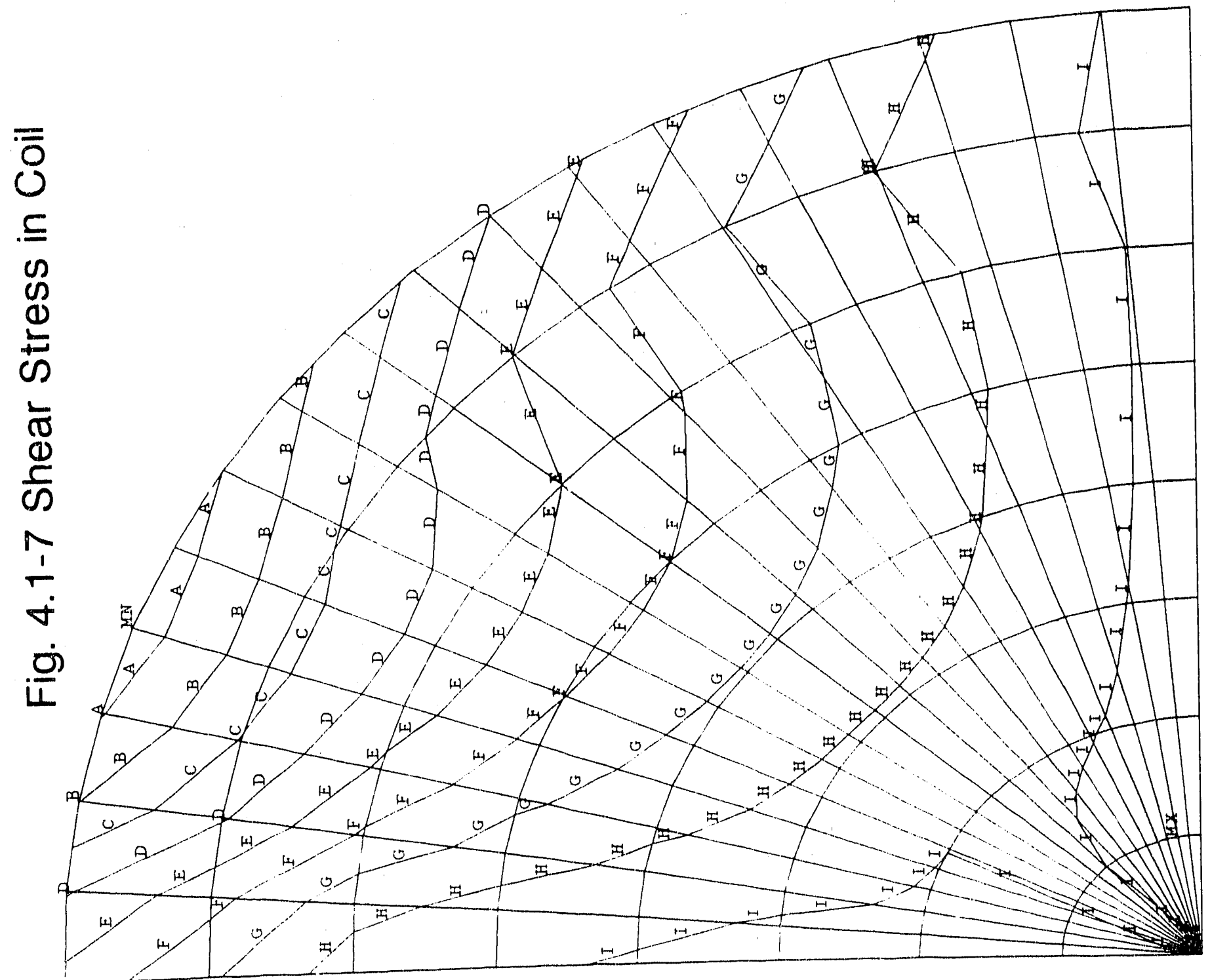

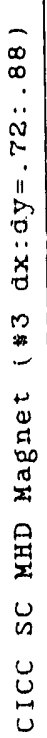




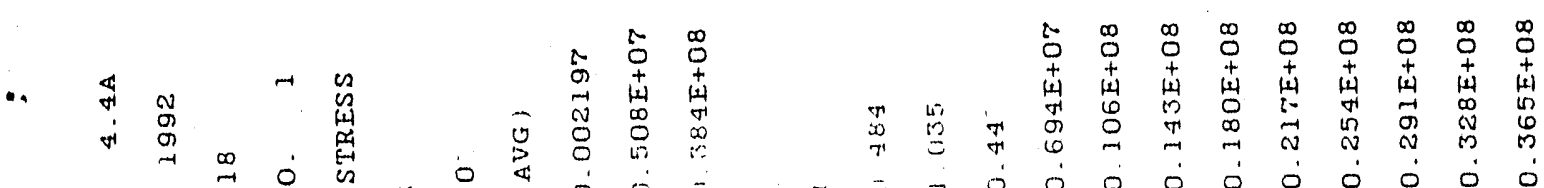

帛

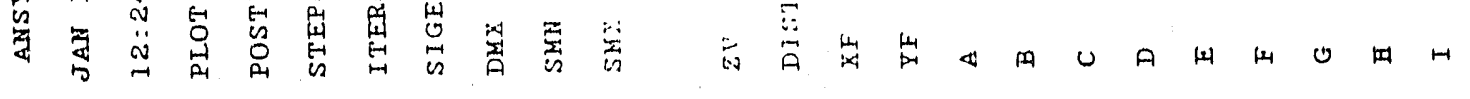

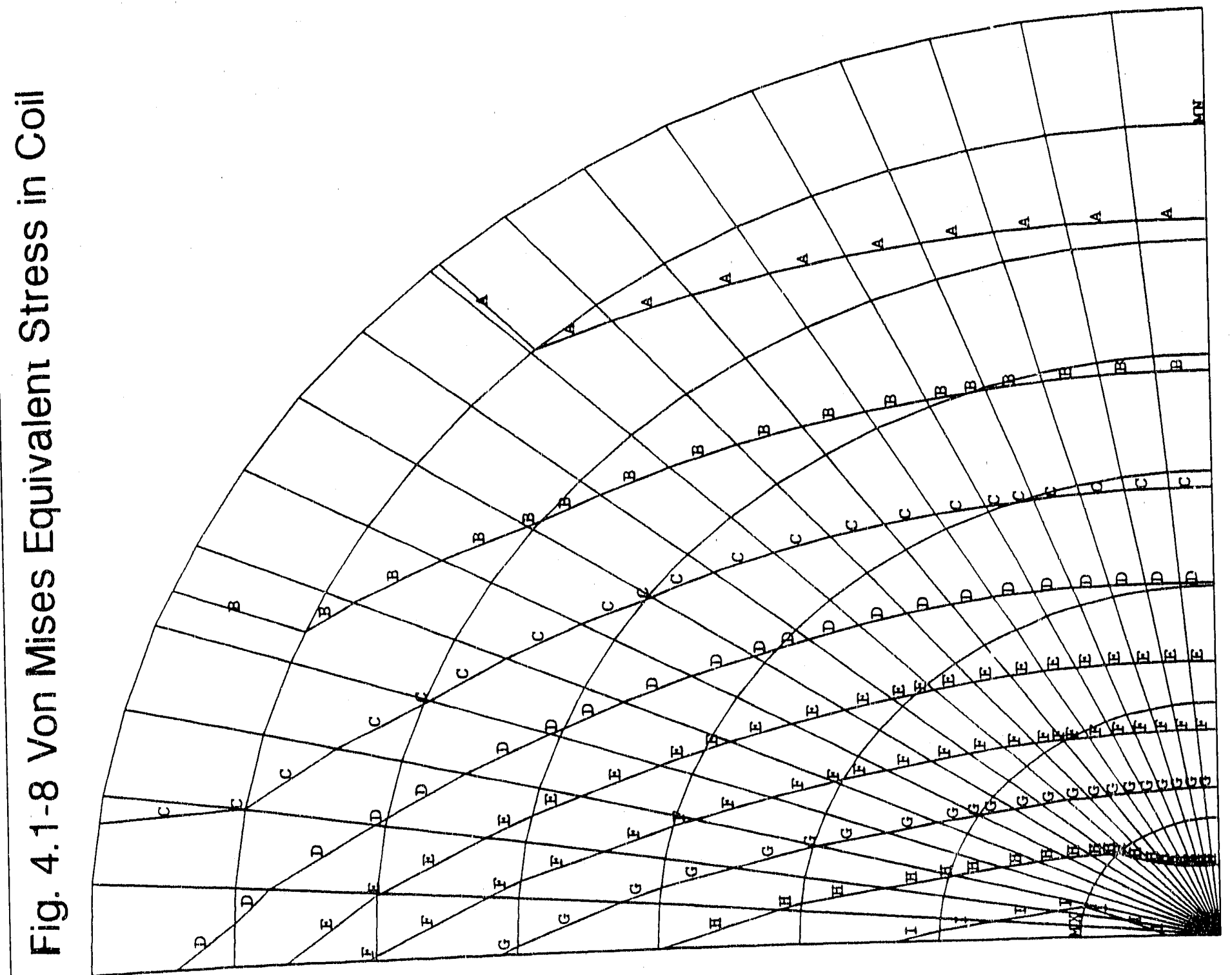




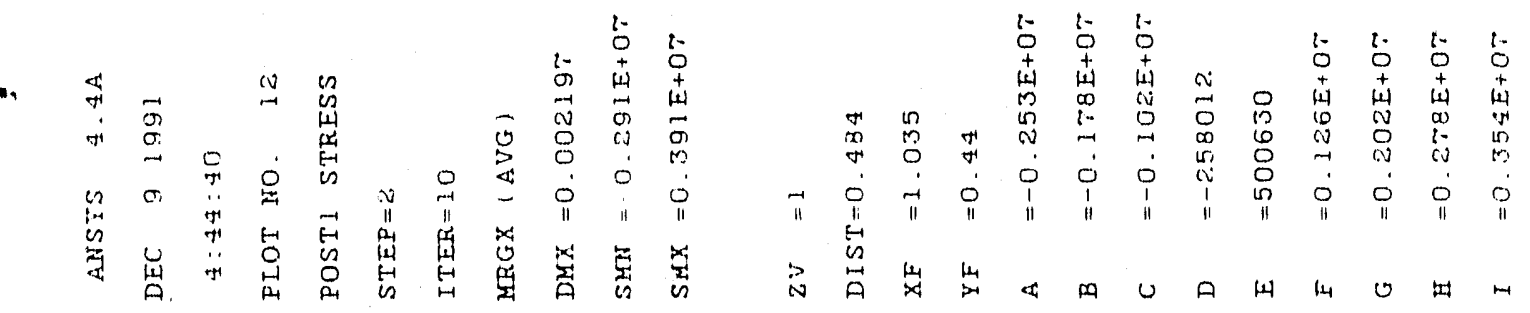

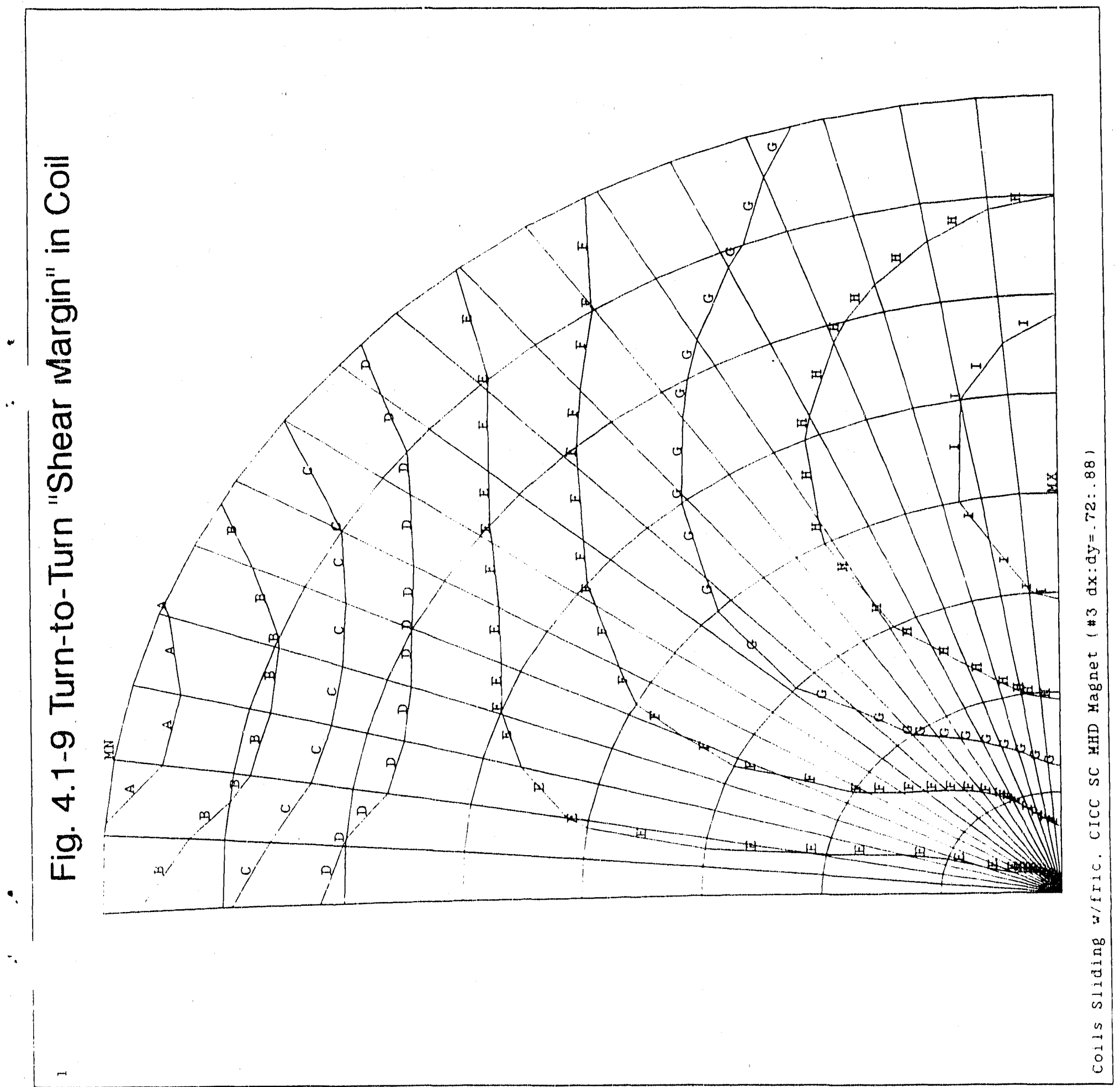




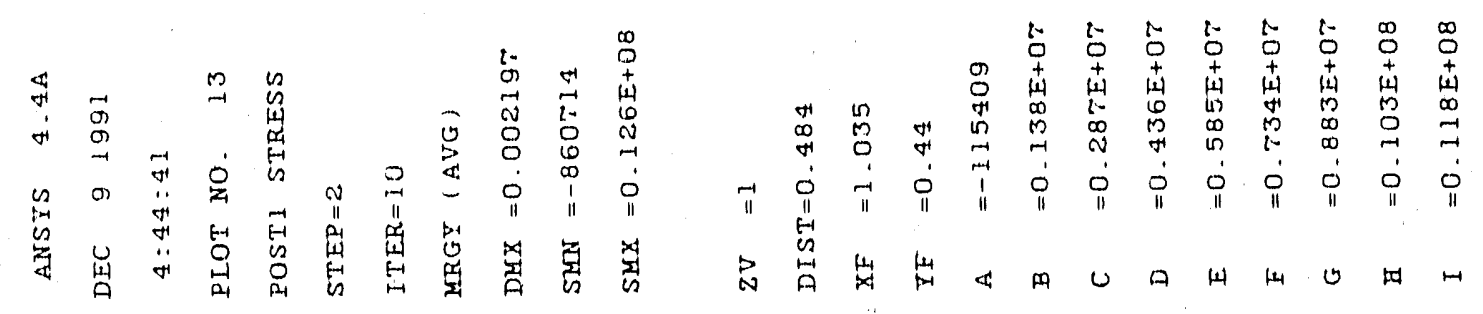

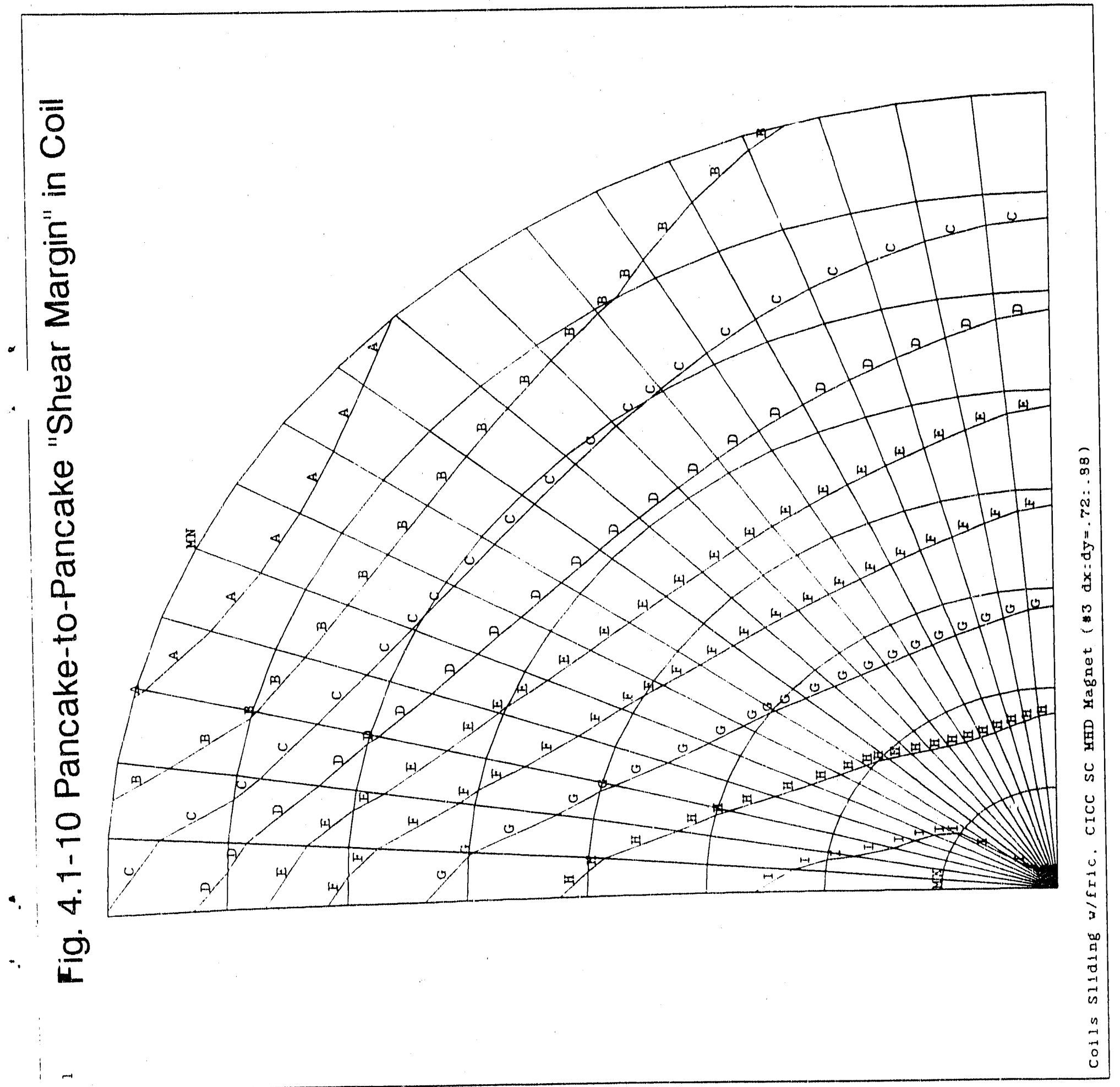




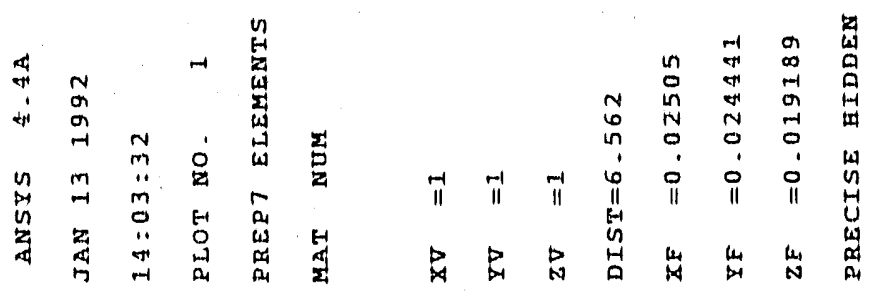

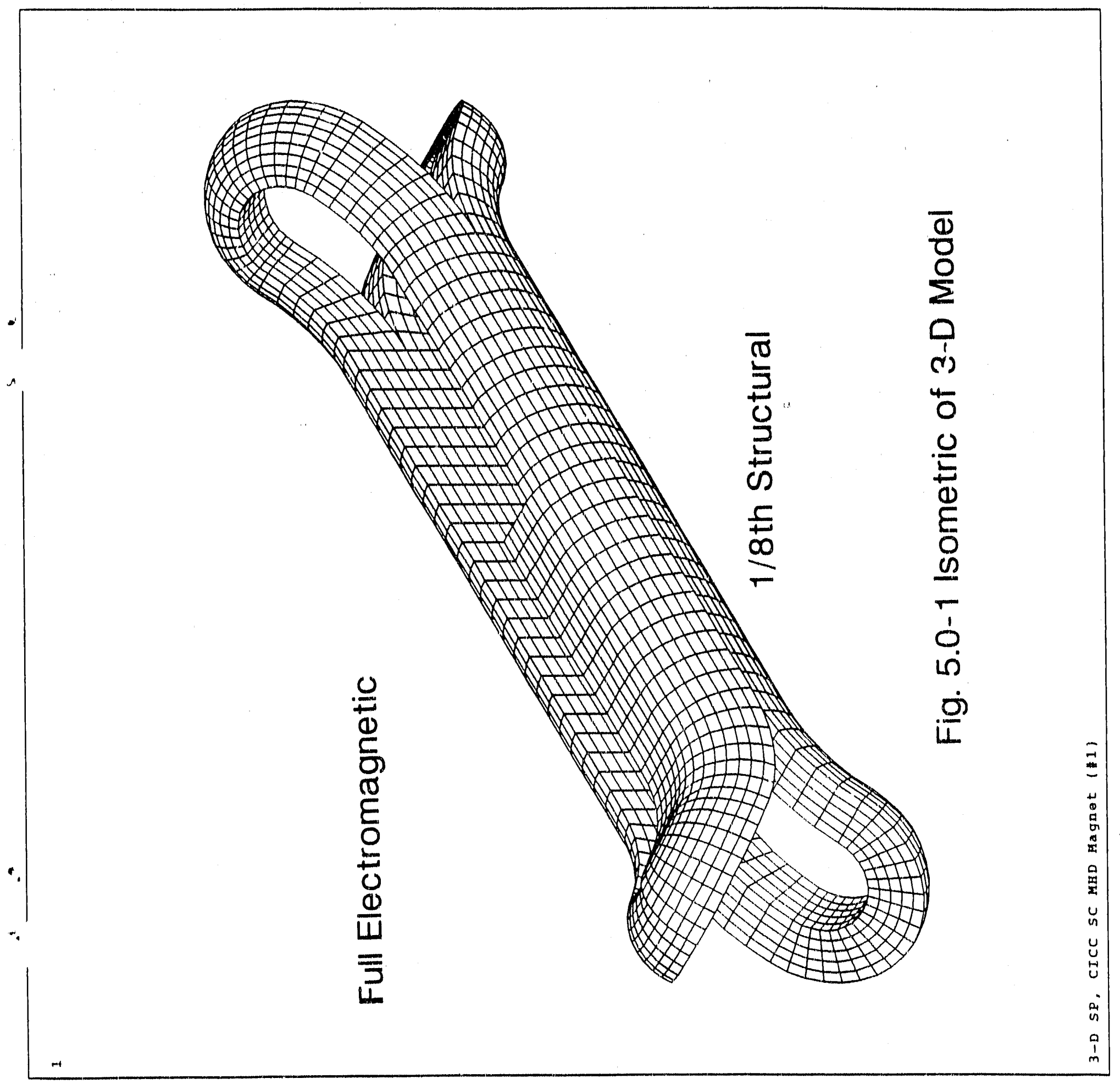



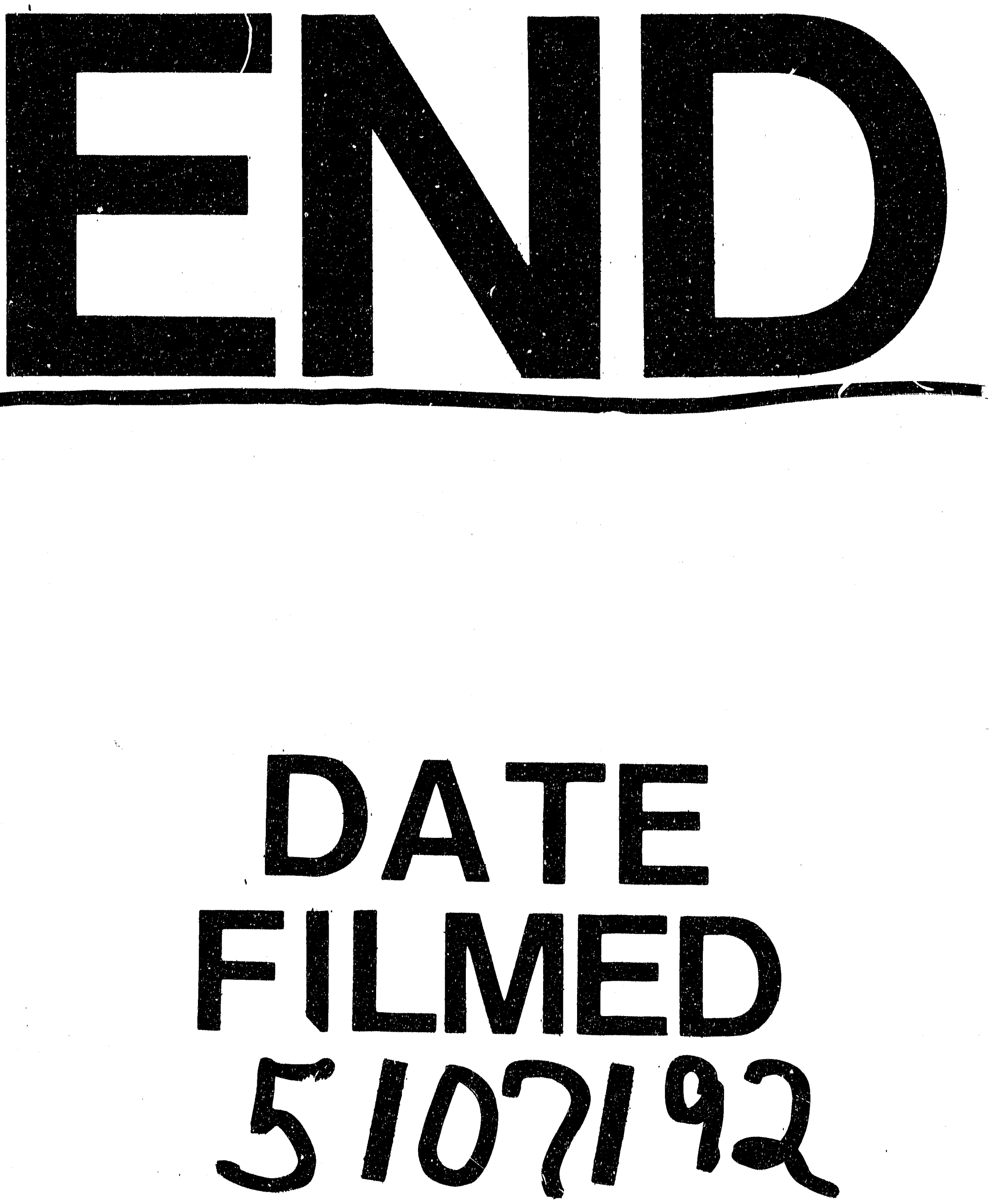
